\title{
European clinical guidelines for Tourette Syndrome and other tic disorders. Part I: assessment
}

\author{
Danielle C. Cath · Tammy Hedderly • Andrea G. Ludolph · Jeremy S. Stern • \\ Tara Murphy • Andreas Hartmann • Virginie Czernecki • Mary May Robertson • \\ Davide Martino $\cdot$ A. Munchau $\cdot$ R. Rizzo $\cdot$ the ESSTS Guidelines Group
}

(C) The Author(s) 2011. This article is published with open access at Springerlink.com

\begin{abstract}
A working group of the European Society for the Study of Tourette Syndrome (ESSTS) has developed the first European assessment guidelines of Tourette Syndrome (TS). The available literature including national guidelines was thoroughly screened and extensively discussed in the expert group of ESSTS members. Detailed clinical assessment guidelines of tic disorders and their comorbidities in both children and adults are presented. Screening methods that might be helpful and necessary for specialists' differential diagnosis process are suggested in order to further analyse cognitive abilities, emotional functions and motor skills. Besides clinical interviews and
\end{abstract}

Members of the ESSTS Guidelines Group are given in Appendix.

D. C. Cath $(\bowtie)$

Department of Clinical and Health Psychology,

Utrecht University/Altrecht Academic Anxiety Outpatient

Services, PO Box 80.140, 3508 TC Utrecht,

The Netherlands

e-mail: D.Cath@uu.nl

T. Hedderly

Tourettes Clinic-Evelina Childrens Hospital at Guys

and St. Thomas', Kings Health Partners AHSC,

London, UK

A. G. Ludolph

Department of Child and Adolescent Psychiatry,

University of Ulm, Ulm, Germany

J. S. Stern

UK Tourette SyndromeAssociation,

Department of Neurology, St George's Hospital,

London, UK

T. Murphy

Tourette SyndromeClinic, Great Ormond Street Hospital NHS

Trust, London, UK physical examination, additional specific tools (questionnaires, checklists and neuropsychological tests) are recommended.

Keywords Tics $\cdot$ Tourette $\cdot$ Assessment $\cdot$ Guidelines

\section{Introduction}

Tics are defined as sudden, rapid, recurrent, non-rhythmic motor movements or vocalizations usually appearing in bouts while waxing and waning in frequency, intensity and

\author{
A. Hartmann · V. Czernecki \\ Centre De Référence National 'Syndrome Gilles de la Tourette', \\ Pôle des Maladies du Système Nerveux, \\ Groupe Hospitalier Pitié-Salpêtrière, Assistance Publique \\ des Hôpitaux de Paris, Paris, France
}

\begin{abstract}
A. Hartmann · V. Czernecki
Centre de Recherche de l'Institut du Cerveau et de la Moelle épinière (CRICM), UPMC Université Paris 6, Paris, France
\end{abstract}

M. M. Robertson

Department of Mental Health Sciences, UCL, London, UK

D. Martino

Department of Neurological and Psychiatric Sciences,

University of Bari, Bari, Italy

\footnotetext{
A. Munchau

Department of Neurology, University Hospital Medical Centre, Hamburg, Germany

R. Rizzo

Department of Child and Adolescent Neurology and Psychiatry, Catania University, Catania, Italy
} 
kind of tic [1]. Tic disorders including Gilles de la Tourette or Tourette Syndrome (TS) typically onset in childhood mostly at the age of 5 to 6 years $[2,3]$. TS encompasses the combination of chronic (more than 1 year) motor and vocal tics. TS is often underdiagnosed and many patients do not receive adequate information and care [5, 6], and thus suffer from psychosocial impairment for a long time. On average, it takes more than 5 years from first onset of symptoms to diagnosis [7]. Patients and their families are frequently unable to correctly identify the symptoms and patients sometimes get stigmatised as a consequence of their tics. Therefore, they often experience a great relief to get a diagnosis because this allows them to better cope with the situation. There is no cure for TS, therefore, treatment aims to diminish tic severity and frequency. Often it is more important to manage the commonly comorbid conditions in order to improve psychosocial functioning and development. So far, to the best of our knowledge, only in Germany explicit guidelines for the diagnosis and treatment of TS exist (German Guidelines of child and adolescent psychiatry [8] and neurology [9]). In the past years, there has been an increasing interest in research on aetiology, pathophysiology, diagnosing and treatment of TS, leading to valuable new insights on many aspects of the syndrome. Therefore, experts of the European Society for the Study of Tourette Syndrome (ESSTS) have developed the first European guideline in four parts (this issue). This part deals with the assessment of tic disorders in children, adolescents and adults.

\section{Epidemiology of tics}

\section{Prevalence}

TS affects between 0.3 [10] and 1\% [11] of the population, a.o. depending on age of the study group and rigorousness of the sampling method used. Tics occur predominantly in young people (before age 18), and tend to have a waxing and waning course [12]. Importantly, a TS diagnosis is twice more likely to occur in non-Hispanic white persons than in Black persons or in Hispanics [10]. There is a male to female preponderance of between $3: 1[10]$ and 4.3:1 $[13,14]$.

\section{Course}

The mean age at onset is around 5 years although lower ages at onset are reported in up to $40 \%$ of persons. Waxing and waning is the rule. Complex tics generally appear later than simple ones and phonic tics appear later than motor tics [15], usually after 1 or 2 years, with $<5 \%$ of patients developing phonic tics first [16]. For most patients, the worst ever period of tics occurs between $8-12$ years of age $[17,18]$.

The course of tics is relatively favourable over time. Clinical as well as population-based studies indicate that up to $80 \%$ of persons who have presented with a tic disorder before age 10 experience a significant tic decrease during adolescence, and by age 18 tic intensity and frequency has decreased to such an extent that the person no longer experiences any impairment from tics, although objective ratings indicate that most persons still have mild tics [19]. Yet, a small proportion of patients (20\%) does not experience a decrease in tic intensity, and in this group some individuals not only experience tic worsening in adulthood but develop the most severe and debilitating forms of tic disorders. Reports on whether certain types of tics in childhood predict tics or comorbidity in adulthood are somewhat conflicting [20-26]. Frequency and severity of tics in childhood is hardly predictive of tic severity in adulthood [22]. However, children and adolescents with tics experience worse quality of life than healthy children (but better than psychiatric controls) [27], and poorer quality of life is related to increased tic severity [28]. Poor quality of life in adults with TS is associated with persistence of OCD [29]. Comorbid OC symptoms in children with TS onset at a somewhat later age (around 10 years) than tics and, in children with tics, tend to remit in only about $40 \%$ of patients [29]. Further new onset of OCD at a later age might occur [12]. Interestingly, persistence of OC symptoms into adulthood is particularly related to high IQ, and to smaller caudate volume measures in children $[23,30]$.

ADHD symptoms in TS children occur in the majority of cases before tic onset, and in one third of children after tic onset [31]. ADHD symptoms tend to decrease in $20 \%$ of children during adolescence but later than tics. Interestingly, OC symptoms in childhood predict OC symptoms and more ADHD symptoms in adolescence and adulthood, and ADHD in childhood predicts more OCD in adulthood $[17,26]$. Finally, persistence of ADHD into adulthood is related to poorer psychosocial functioning. In conclusion, the following picture emerges: as tics in childhood hardly predict long-term outcome, comorbid OCD and ADHD are associated with poorer psychosocial functioning.

\section{Pathogenesis}

Family studies of TS consistently show a 10 - to 100 -fold increase in the rates of tics and TS in first degree relatives of TS patients compared to control families, indicating a strong genetic component to be operant in the disease [31-33]. Tic severity increases with bi-lineal transmission [34]. Further, independently of whether the proband has 
concurrent OCD, first degree family members of TS patients have elevated rates of early-onset OCD, especially the female relatives, suggesting that-in TS-OCD is an alternate expression of the TS phenotype [32]. With respect to ADHD transmission, the picture is slightly different; although rates in first degree relatives of TS families are significantly elevated, ADHD is mostly comorbid with tics in the relatives, pointing into the direction of shared aetiology, i.e. associated but not comorbid in the strict sense [35], and not ADHD as an alternate expression of the disease [31]. In summary, these family studies strongly indicate a genetic component to be operant in TS, with shared genetic influences between tic and OCD, but it is unclear for ADHD. A large Genome Wide Association Study within the TSA genetic consortium is underway [36] (for a review on the genetics of TS: see O'Rourke et al. [37]).

MRI studies with different techniques [38-43] and electrophysiological investigations [44] on neuronal inhibition have identified alterations in brain areas of the cortico-striato-thalamo-cortical (CSTC) circuits. Finally, PET raclopride studies using amphetamine challenge to study D2 receptor availability in striatal circuits in TS patients have revealed increased phasic dopamine release in ventral striatal areas in TS patients after amphetamine challenge $[45,46]$ (Table 1).

\section{Diagnosing}

Tics can either be diagnosed according to the tenth International Classification of Disease (ICD)-10 criteria or according to criteria of the Diagnostic and Statistical

Table 1 Clinical features of tic disorders to be distinguished from similar phenomena of other disorders; MED medication induced

\begin{tabular}{ll}
\hline Tic phenomena & Differential diagnosis \\
\hline Eye rolling & Absences \\
Focussing on tic control & Attention problem \\
$\begin{array}{l}\text { Tic repetition (after } \\
\text { post-tic urge) }\end{array}$ & Obsessive-compulsive behaviour \\
'Excessive" tic & Imitation/somatisation \\
Tripping & MED-akathasia, juvenile Parkinson \\
& desease/OCB \\
Neck jerking a.o. & Dystonia, MED-dyskinesia \\
Convulsive grimacing & Blepharospasmus/Facialis spasm \\
'Slinging' tics & Chorea \\
'Trembling' tics & Myoklonus \\
Monotone tic ('rhythmic') & Stereotypy \\
Tics during sleep & Restless legs/Rolandi epilepsia/ \\
& parasomnias \\
Excesive eye squeezing & Blepharospasm \\
in adults & \\
\hline
\end{tabular}

Table 2 Differences of motor symptoms in ADHD and tic disorders

\begin{tabular}{|c|c|}
\hline Tic disorders & ADHD \\
\hline Fragments of normal movements & $\begin{array}{l}\text { Generally increased motor } \\
\text { activity }\end{array}$ \\
\hline $\begin{array}{l}\text { Circumscribed functional muscle } \\
\text { groups }\end{array}$ & General motor hyperactivity \\
\hline $\begin{array}{l}\text { Suddenly occurring (independent } \\
\text { of waiting situation) }\end{array}$ & $\begin{array}{l}\text { Slowly increasing (intensified by } \\
\text { waiting situation) }\end{array}$ \\
\hline Fixed pattern of quick actions & Disorganised, tempo change \\
\hline Badly modulated & Badly modulated \\
\hline $\begin{array}{l}\text { Uniformly repeated (often in } \\
\text { bouts) }\end{array}$ & $\begin{array}{l}\text { Temporally irregular-intermittent } \\
\text { (changing intensity) }\end{array}$ \\
\hline
\end{tabular}

Manual Text Revision, fourth edition (DSM-IV-TR) [47]. These classification systems are fully compatible. According to DSM-IV-TR criteria, tic disorders are grouped under the disorders that first occur in infancy, childhood or adolescence, and encompass four categories, i.e. Tourette's disorder (307.23), chronic motor or vocal tic disorder (307.22), transient tic disorder (307.21) and tic disorder not otherwise specified (307.20) (Table 2). In ICD 10 , the same categories exist and the differences are minimal. In DSM-IV-TR [4] one item has been omitted that is mentioned for nearly all mental disorders and has previously been necessary for the diagnosis of TS: "The disturbance causes marked distress or significant impairment in social, occupational or other important areas of functioning". This modification was made in recognition of the fact that clinicians see patients who meet all the other criteria for TS, but do not have distress or impairment.

For DSM-V (expected in 2013), only minor changes have been recommended, designed to clarify and simplify the diagnostic criteria, and reduce the use of the tic disorder not otherwise specified category. A European commentary on recent DSM-V version can be found in this Journal [48]. Specific recommendations include a.o: (1) simplification of the duration criterion for the tic disorders; any person who has tic symptoms of less than 12 month duration but more than 4 weeks duration receives the diagnosis 'provisional tic disorder'; (2) establishing new tic disorder categories for substance induced tic disorder and tic disorder due to a general medical condition; (3) including a motor tic only and vocal tic only specifier for the chronic motor or vocal tic disorder category [49].

To establish a diagnosis of TS, a person must have (1) the combination of two or more motor tics and one (or more) phonic tic, that have been present at some time during the illness although not necessarily concurrently; (2) tics occur many times daily nearly every day through a period of more than 1 year; (3) onset before 18 years of age; and (4) are not directly caused by a general medical condition or by substance use. 
Motor tics are described as brief, sudden, irresistible, inapposite and non-rhythmic recurrent movements in voluntary muscles or muscle groups [50]. Most common tics occur in the face, neck or shoulder musculature and encompass a.o.: eye blinking, nose and mouth twitches and shoulder jerks.

Vocal tics are defined as sounds elicited by a flow of air through the vocal cords, mouth or nose and the most common vocal tics are: throat clearing, grunts, high-pitched sounds and sniffing. Amongst the most well-known vocal tics is coprolalia (i.e. the uttering of socially inappropriate words), which occurs only in between 14 and $20 \%$ of patients [51]. Tics can be suppressed or inhibited depending on the situation. The suppression, however, causes an uncomfortable sensation.

Three essential 'tic' features can be recognised that are closely interwoven, i.e.: (1) temporary tic suppression [16]; (2) inner tension that accompanies tic suppression; (3) the feeling of active involvement in performing a tic, especially in adults. Although patients cannot permanently suppress the tic they might experience the tic as a conscious, intentional and self-directed movement executed to relieve a premonitory urge [52]. This feeling of intentionality is rarely present in children between age 4 and 8 but increases with age, and by age 12 the majority of patients recognises a premonitory urge preceding and exacerbating a tic [15]. This subjective perception is an important distinguishing feature from other hyperkinetic movement disorders [52].

Tics usually start in the face and tend to extend caudally, with a remaining preference for head, neck, shoulders and arms. Tics tend to significantly decrease during sleep, although - in contrast with previous notions - they often do not disappear [53]. Up to $60 \%$ of TS children and adults complain about disturbed sleep [54]. Polysomnography and simultaneous video recording during sleep in TS patients has revealed both an increased number of regular movements and more tics in all sleep stages but especially during REM sleep [53, 55, 56]. Patients show decreased sleep efficiency and slow wave sleep percentage, increased sleep latency, more awakeness and awakenings and more sleep stage changes during sleep. Severity of TS is positively associated with number of awakenings and sleep stage changes and negatively with sleep efficiency. Comorbid ADHD, a condition in which increased motor activity during sleep is found as well, seems to significantly add to the sleep problems in TS [56-58].

The intensity of tics depends in most cases on environmental cues, such as exciting or stressful events, although the nature of these environmental mediators has hardly been investigated systematically yet. In apparent contrast to this, tics can exacerbate during relaxation, for example whilst watching television. Situations or activities that require focused attention from the patient often diminish tics, both in children and adults [59].

\section{Types of tics}

Tics can be classified according to: type, complexity, whether they are isolated or multiple, and according to location, number, frequency and duration [6]. They also vary in terms of intensity or 'forcefulness' [69].

Type

Tics can be motor, vocal, sensory or cognitive [60].

\section{Motor tics}

Motor tics arise in the voluntary musculature and involve discrete muscles or muscle groups. Tics can be seen as fragments of normal motor movements that appear out of context [61]. The most frequent tic is eye blinking. [16].

\section{Phonic (or vocal) tics}

Phonic (or vocal) tics can consist of any noise produced by movement of air through the nose, mouth or pharynx. Tongue clicking is, therefore, not classified as a phonic, but a motor tic. The term 'phonic' should be preferred over 'vocal', since not all sounds (f.i. sniffing) are produced by the vocal cords. Less than $5 \%$ of patients with tics have phonic tics alone without associated motor ones [62], but motor tics without phonic tics are very common.

\section{Sensory tics}

Many adult patients (up to 90\%), are aware of premonitory sensations preceding the tics, with a mean age of starting to become aware of 10 years, and depending on type of tic [15]. More automatic movements such as eye blinking are less often preceded by sensory urges. These sensations are experienced as unpleasant somatosensory sensations, either within the muscles of the upcoming tic or somewhere else in the body or the head (tiredness, itch, pressure, stabbing pain, abdominal discomfort, heat or cold) and sometimes difficult to articulate. They are often relieved by execution of the tic $[52,63]$. Younger children are much less aware of premonitory urges; $37 \%$ of children between 8 and 19 years are able to report on premonitory urges, whereas $64 \%$ of these children were able to suppress their tics. Thus, tic awareness does not seem to be a prerequisite for the ability to suppress tics, and awareness seems to increase with age, and be closely associated with cognitive development [64]. Premonitory urges can be bound to small 
localised areas, with 'hot spots' in the shoulder girdle, hands, feet and front of the thighs. They can also be more generalised, and described as a sense of 'inner tension' [61].

\section{Cognitive tics}

These tics have been described in adolescents and adults with TS and seem to occur predominantly in this age group [65-67]. They have been first described by Shapiro et al. [16] and termed 'impulsions' to delineate them from the anxiety-driven 'obsessions' that occur in 'pure' OCD patients. Thus, cognitive tics are described as repetitive thoughts that are not anxiety-driven but occur as a response to the excessive urge to give in or act upon provocative auditory, visual, tactile or inner stimuli [67]. Although exact frequencies are not known, cognitive tics encompass: echophenomena in thought, mental play [68], aimless counting and repetitive thoughts with sexual or aggressive content that produce no fear.

\section{Complexity}

Tics can be subdivided into simple and complex [62]. Simple tics are restricted to one muscle or a single muscle group. Examples of simple motor tics are: eye blinking, nose twitching, tongue protrusion, head jerks and shoulder shrugs, etc. Examples of simple phonic tic are grunting, throat clearing, coughing, sniffling and barking, etc.

Complex motor tics often have a repetitive and/or compulsive nature. Examples are: the repetitive touching of objects or people, making elaborate sequences of movements, repetitive obscene movements (copropraxia), mimicking others (echopraxia) or wounding oneself (selfinjurious behaviour). Complex phonic tics occur when sounds are elaborate or have a semantic content, including for instance words or phrases, expressing obscenities (coprolalia), repeating others (echolalia) or repeating oneself (palilalia). In general, complex motor tics are aimless or in response to an excessive premonitory urge. However, when the tic sequences are complex and elaborate it can be difficult to distinguish them from compulsions as seen in 'pure' OCD, the latter being more cognitively driven, goal-directed and aimed at reduction of anxiety [15].

\section{Isolated or multiple}

One can have one tic that always originates from the same anatomical location (isolated) or many tics at multiple locations. Migration of tics from one location to another over longer periods of time is typical in chronic tic disorders. The tics wax and wane in intensity and complexity.

Duration

Tics are generally brief. They can be categorised as clonic (less than $100 \mathrm{~ms}$ ) or dystonic and tonic (more than $300 \mathrm{~ms}$ ). Dystonic tics are less common and are characterised by a repetitively abnormal posture of a kind that one may see in dystonia (e.g torticollis). In tonic tics, there is a relatively long duration of the contraction (in e.g. back muscles) without exhibiting abnormal postures.

\section{Impairment}

In children and in adults, it is paramount to assess degree of impairment due to tics or comorbid conditions, although as described here above, in DSM-IV-TR [4] and in future DSM-V [49], the distress item has been omitted that was obligatory to establish a tic diagnosis in previous classifications. Impairment entails that the disorder is time consuming, causes significant distress and interferes with major domains of daily life of both children and adults, such as school, work status and (social) relationships. Impairment can be reliably measured with various instruments, including the impairment item on the Yale Global Tic Severity Scale (YGTSS), which separately rates impairment due to motor or vocal tics, on 0-4 scales [69]. Alternatively, impairment can be assessed using a Global Assessment of Functioning, both in children (C-GAS) [70] and in adults according to axis five of DSM-IV TR (2002 [47]). The scale runs from $0-90$, with 0 indicating complete dependence on care by others, and 90 being healthy and excellently functioning in all areas of development, school/ work and psychosocial functioning. Further, in children as well as adults the Clinical Global Impression Scale (CGI-S [71]) can be rated by the clinician. The CGI-S assesses change in global daily functioning (between $0=$ much deteriorated and, via $3=$ no change, to $6=$ very much improved). The CGI-S has shown good face validity and is extremely easy to use, although interrater reliability is somewhat low [72].

Recently, a Quality of Life scale has been developed specifically for tic disorder patients [73, 74]. This 27 item scale is based on the health-related quality of life scale (HR-QOL) [75] with response ranges between 0 and 4, and assesses quality of life in four domains: psychological problems, cognitive problems, physical/Activity of Daily Living problems and obsessive-compulsive themes. Internal consistency as well as test-retest reliability are excellent. TS patients report elevated scores, predominantly in the domains of psychological and cognitive problems [73]. 


\section{Comorbidity}

In clinical series, the large majority of cases (79\%) have comorbid psychopathology, with attention deficit/hyperactivity disorder (ADHD) predominantly of the inattentive or combined subtype, being the most frequent comorbid disorder in up to $60 \%$ of the cases in both children and adults [31], followed by Obsessive-Compulsive Disorders (OCD), merely in adolescents and adults, anger control problems, sleep disorder, learning disorders, mood disorders, anxiety disorders and conduct and oppositional defiant disorders (CD/ODD). Sex differences occur with respect to this comorbidity, with predominance of males over females for ADHD, CD/ODD, anger control problems and learning disorders, and a female preponderance for OCD and self-injurious behaviour. Other comorbidities include impulsive, self-injurious and aggressive behaviour, autism spectrum disorders and sleep disorders [76]. Especially in adults, comorbidity often forms the main reason to seek help.

\section{Differential diagnosis}

Tics need to be differentiated from other hyperkinetic movement disorders and from psychogenic movement disorders (Table 3). The features that distinguish tics from other movement disorders-with the exception of akathisia and psychogenic movement disorders-are (1) the ability

Table 3 Clinical differences and similarities of tic disorders and obsessive-compulsive disorders

\begin{tabular}{ll}
\hline Tic & Obsessive-compulsive disorder \\
\hline $\begin{array}{l}\text { Differences } \\
\text { Sudden, short (jerking) }\end{array}$ & $\begin{array}{l}\text { Ritualized } \\
\text { Fragmented movements }\end{array}$ \\
$\begin{array}{l}\text { Gensor-directed behaviour } \\
\text { Thoughts/imaginations (cognitive- } \\
\text { emotional dissonance) }\end{array}$ \\
$\begin{array}{l}\text { Not related to anxiety } \\
\text { Ego-syntonic }\end{array}$ & $\begin{array}{l}\text { Mostly related to anxiety } \\
\text { Involuntary (clustered } \\
\text { sequence) }\end{array}$ \\
$\begin{array}{l}\text { Onset in primary school (one } \\
\text { peak) }\end{array}$ & $\begin{array}{l}\text { Onset after primary school (two } \\
\text { peaks) }\end{array}$ \\
$\begin{array}{l}\text { Waxing and waning (from } \\
\text { seconds to months) }\end{array}$ & Little changes over time \\
Also during sleep & Never during sleep \\
Similarities & \\
Decrease with concentration & Decrease with concentration \\
Increase with emotional & Increase with emotional excitement \\
excitement & \\
Suppressible (short-term) & Suppressible (long-term) \\
\hline
\end{tabular}

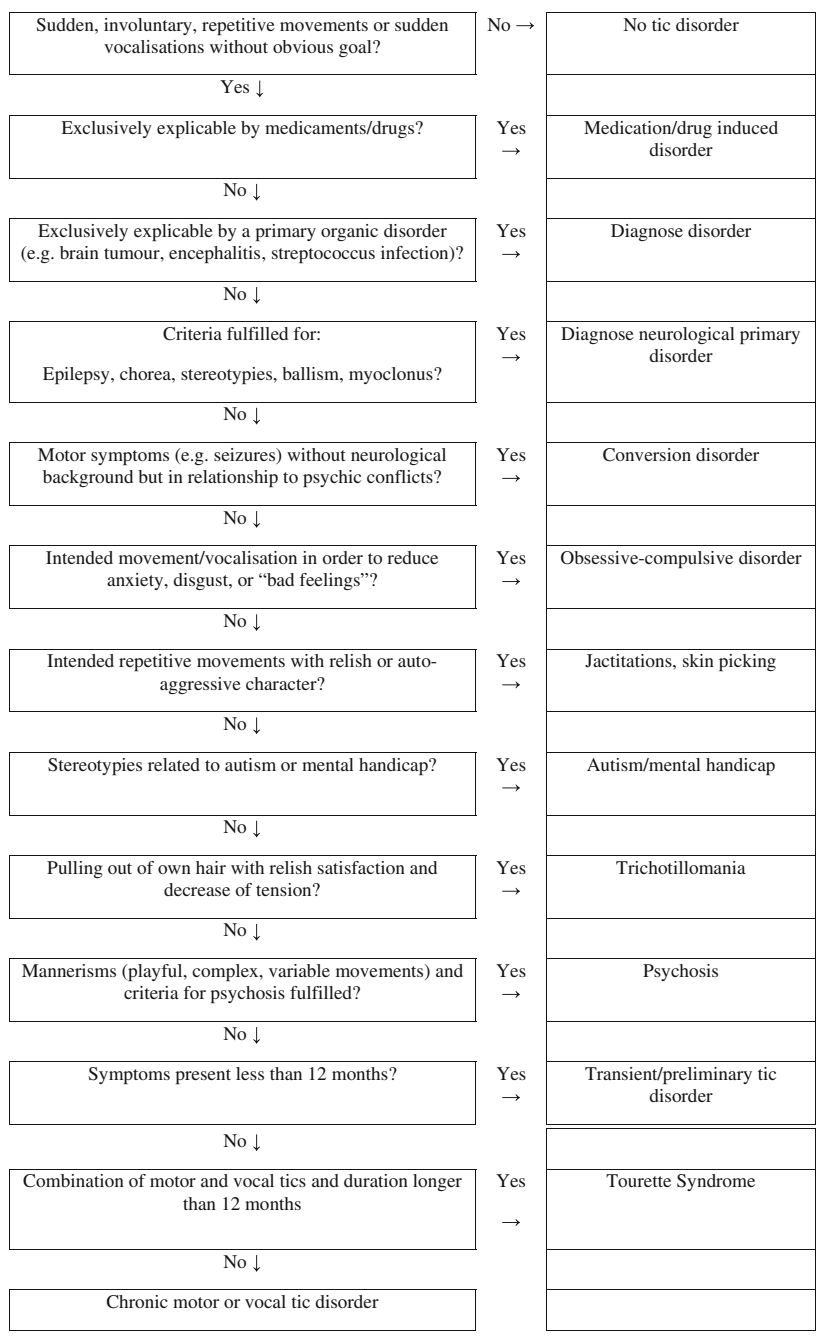

Fig. 1 Differential diagnostic decision tree for tic disorders

to suppress them for a while, and (2) the patient's experience of tics as a (partly) voluntary movement to relieve an inner tension or a premonitory focal sensory sensation [77]. These features can be used to help differentiate from other movement disorders which characteristically worsen with action and are not suppressible [78] (Fig. 1).

\section{Work up}

\section{General evaluation}

A general evaluation of both children and adults includes assessment of the most debilitating complaints and symptoms, assesses how the symptoms developed and inquires about potential stressors and triggers. Especially in children, a developmental history is obtained. In children and adolescents, family functioning is assessed including parental coping styles and parental conflict, social network 
and financial \& housing situation. In adults, partner status, current work and financial/housing situation is assessed as well. Moreover, if available hetero-anamnesis on tic and disease status is obtained from a partner, spouse or confidential person in the vicinity of the adult patient.

\section{Parent- and patient rating scales to support the general evaluation}

In children, adolescents as well as adults, it is highly advisable to supplement clinical interviewing with screens that rate general psychopathology. In children and adolescents, these are parent and/or teacher-derived, in adolescents complemented with self-reports, and in adults self-reports are taken, when necessary complemented with heteroanamnestic assessments of a partner, parent or other person in the neighbourhood of the patient.

Self-report scales are recommended to provide general information on psychopathology. In children and adolescents, the parent-derived Child Behaviour checklist (CBCL) or-in adolescents and adults-the Young Adolescent Self-report or Youth Self-report which is fully in line, is highly recommended [79-81]. The same holds true for the SDQ (Strengths and Difficulties Questionnaire [82]; see also internet at www.sdqinfo.com). These scales are well validated across the different age groups, providing the clinician with the opportunity to follow children across the lifespan essentially using the same scale.

A detailed medical history is conducted (including medication and drug consumption in pregnancy by the mother, birth history, early development and past medication use by the patient etc.), and a complete psychosocial and family history to detect psychiatric and/or neurological conditions in relatives.

Interviews to assess disorders of infancy, childhood and adolescence including tics are abundant in child psychiatric settings. Various interviews are (1) compatible with international diagnostic systems (DSM-IV and/or ICD-10), and (2) explore the whole range of childhood derived disorders [83]. These are: the Diagnostic Interview Schedule for Children (DISC) [84, 85], the Children's Interview for Psychiatric Syndromes (ChIPS) [86], the Schedule for Affective Disorders and Schizophrenia for School-Age Children (Kiddie-SADS-PL; http://www.wpic.pitt.edu/ ksads/default.htm; [83, 87], the Diagnostic Interview for Children and Adolescents (DICA[88]; psychometrically weak), the Child and Adolescent Psychiatric Assessment (CAPA) [89], of which young adult and young children versions are available; and the Interview Schedule for Children and Adolescents (ISCA [90]). All interviews are administered by clinicians and include a child/adolescent version and a parent version. In general, children seem to be better informants in describing internalising disorders, and adults (parents, teachers) more reliably describe externalising disorders [83]. The ISCA and the CAPA also explore on DSM-IV axis II diagnoses. Inter-rater reliability appears to be good for the 6 instruments, with kappa's ranging from 0.5 to 1 . Overall, the K-SADS-PL has the best test-retest reliability [91] and is mostly used across countries, but takes somewhat lengthy interviewing (between 1 and $3 \mathrm{~h}$ ).

Notably, in adults, no structured interviews are available that include the full range of disorders of infancy, childhood and adolescence including tic disorders. The most used instruments to assess other comorbid disorders are the Structured Clinical Interview on DSM-IV axis I disorders including the TR form (SCID-I [47, 92]; between 1 and $2.5 \mathrm{~h}$ ), and the Mini International Neuropsychiatric Interview (MINI), which is an abbreviated version of the SCIDI and takes between $30 \mathrm{~min}$ and $1 \mathrm{~h}$ to complete [93]. Both the SCID-I and the MINI require training.

Specific evaluation

\section{Clinical interview}

Age of onset of first tics should be recorded, as well as tic history and course and age at worst tic severity. Further, inquiries are made about which tics (or comorbid conditions) are considered to be most debilitating, and about their physical consequences (including pain/injury of muscles and joints), about somatosensory phenomena accompanying the tics, tic suppressibility and about exacerbating or relieving factors accompanying the tics (e.g. stress sensitivity). Patients and parents are asked about any possible relationship between infections (throat, ear) and tic exacerbation, to determine whether streptococcal autoimmunity could be a factor (e.g. in relation to Pediatric Autoimmune Neuropsychiatric Disorders Associated with Streptococcus (PANDAS) [94]). Patients and family members are questioned about the circadian profile of tic activity (including during sleep), to clarify the psychosocial impact of tics on family functioning, learning and quality of life [74]. Finally, the family history should be pinpointed to specific questions about tics, obsessive compulsive and ADHD behaviours in first degree family members.

The clinical examination is accompanied by standardised assessment of tics, comorbid conditions (including ADHD, OCD, self-injurious and anger control behaviours, mood and anxiety, sleep and learning difficulties) and their severity.

Assessment of tics

A considerable difficulty in assessing and quantifying tics is caused by (1) the spontaneous variations of tics in an 
individual over time, (2) The large variability in impact of a given level of physical tic severity on an individual or their family and (3) the tendency of patients to suppress their tics, especially when in the office with the clinician. Therefore, it is advisable when assessing tics, to use multi informant data, and to combine direct observation (both at home and in the school/work environment), historical information and - if available - to collect video data, in the clinical setting, 'home alone' or both [95]. Additional videotape tic monitoring might enhance capturing the whole tic repertoire of the patient. Various video protocols have been developed and extensively described, usually advising between 5 and $15 \mathrm{~min}$ of videotape recording [95-97].

In general (see Table 5), the evaluation of tics and comorbid symptoms in children and adults is highly comparable, using similar self-report scales and clinicianderived interviews. The differences predominantly lie in the person of the informant. In children this is mostly a parent, in adults the information is obtained-if available-from partner or spouse. In choosing an instrument it is advisable to make a choice based on (1) compatibility of the instrument to international (DSM-IV-TR) criteria; (2) the quality of its psychometric properties and (3) whether it provides scales that are normed across age groups, preferably ranging between infancy and adulthood.

A helpful assessment tool to systematically assess several aspects of the clinical history is of tics is the Diagnostic Confidence Index [98]. The DCI provides a score between 0 and 100 which allows clinicians to measure the likelihood that a person meets criteria of TS. However, validity and reliability criteria are not very well developed.

The most widely used checklists on tic characteristics and severity that combine an observant component and historical information obtained from the patients, parents and or spouses include the YGTSS [69], the Shapiro Tourette SyndromeSeverity Scale (STSSS) [16] and the Hopkins motor and vocal tic scale [99] (for an overview: see Kompoliti and Goetz [100]). The YGTSS includes a clinician-administered inventory of 30 items including 18 categories of motor and vocal tics, self-injurious behaviour and anger control problems to which a severity rating scale has been added. These 10 YGTSS severity items measure the number, frequency, intensity, complexity and interference of motor and phonic tics, and a separate impairment rating on 0-4 scales for each item [69]. Children and adults can be followed using the severity ratings. The YGTSS has high internal consistency and stability [101], convergent validity with other scales and discriminant validity. Overall, the psychometric properties appear to be better than in other scales. Two disadvantages are that time needed to collect information is up to $20 \mathrm{~min}$ and the use of the scale needs some training [100].
The STSSS is developed for clinical trials, encompasses five items including the noticeability to others, and interference of daily life due to tics [102]. The STSS is short, easy to use and reliable with high internal consistency. A limitation is that it does not assess tic characteristics. The Hopkins motor and vocal tic scale focuses both on tics and their impairments, using visual analogue scales on which physicians and parents separately rank motor and vocal tics. Three scores are obtained: a total score, a parent (or partner)-derived score and a rater score. Interrater reliability to evaluate tic severity is equally well as seen in the YGTSS, STSSS and CGI [99].

\section{Assessment of comorbid conditions}

Recommendations are given to assess the most prevalent comorbid conditions, i.e ADHD and OCD. For recommendations on other comorbidities, we refer to Table 4.

\section{ADHD}

To establish the presence and severity of comorbid ADHD, both in children, adolescents and adults, several rating scales can be used to screen on presence of ADHD. However, these scales can only be used as an aid to help diagnosing using standard interviews. With respect to interviews used, assessments should contain key questions for parents (of both children and adults; [103]) on present as well as past performance (starting before age 7) with respect to inattention, impulsivity and hyperactivity. In children, various well validated instruments are used, a.o. the Kiddie-SADS, and the DICA (see here-above). In adults, the picture is less clear, and various interviews, mainly based on DSM-IV criteria of ADHD, have been developed across countries [104]. The particular challenge in assessment of adults lies in the gathering of reliable information on behaviour that has started before age 7 to establish an ADHD diagnosis. This can be extremely difficult, particularly if no informants (parents, older siblings or other family members) are available to provide information on childhood behaviour, and when current comorbid depressive or other psychiatric symptoms hamper reliable information provided by the patient.

ADHD rating scales that are mostly used in children are: the Swanson, Nolan and Pelham questionnaire, 4th edition (SNAP-IV) [105] and the Children's version of the Connors ADHD Rating Scale (CAARS) [106, 107]. The SNAP-IV encompasses a 30 item validated self-report questionnaire with ratings between 0 and 4 per item. Internal consistency, interrater reliability and validity are good. The CAARS (66 item or 30 item versions) has a children's and an adult version and encompasses several subscales with ratings 
Table 4 Features of tic disorders versus stereotypies

\begin{tabular}{lll}
\hline Feature & Tics & Stereotypies \\
\hline $\begin{array}{l}\text { Age at onset (years) } \\
\text { Pattern }\end{array}$ & $6-7$ & $<2$ \\
Movement & Variable & Fixed, identical, foreseeable \\
& Blinking, grimassing, warping, jerking & Arm-hands, wavelike, fluttering, \\
Rhythm & Quick, sudden, aimless, but not rhythmic & Rhythmic \\
Duration & Intermittent, short, abrupt & Intermittent, repeated, prolonged \\
Pre-movement & Yes & No \\
sensorimotor phenomena & & \\
Trigger & Excitement, stress & Excitement, stress, also in case \\
& & of demands \\
Suppressibility & Self-directed, short (associated with & By external distraction, seldom \\
& increased inner pressure) & conscious effort \\
Family history & Often positive & Maybe positive \\
Treatment & Primarily neuroleptics & Rarely responsive to medication \\
\hline
\end{tabular}

between 0 and 4 per item which measure ADHD symptoms, impulsivity, inattention and hyperactivity domains, and (in the long version) ratings with respect to global psychological functioning and self-esteem. The CAARS has the advantages of being thoroughly validated across different age groups, and is suitable to be filled in by multiple informants. The CAARS displays good internal consistency, interrater reliability and validity [103] but has-in adults - the disadvantage of not inquiring retrospectively, although it inquires on whether symptoms have been present before age 7 and caused distress or impairment. An adult self-report rating scale that meets with the criterion of retrospective inquiry on symptoms is the Wender Utah Rating Scale (WURS) [108].

In conclusion, in children the diagnosis of ADHD is more easy to establish than in adults, where assessments with multiple informants should be combined to establish a diagnosis of ADHD [103].

\section{OCD}

Some instruments designed to capture the OCD are suitable as a screener in epidemiological samples, some capture the OCD symptoms in clinical samples and some measure OC severity over time. Reliable screeners are: the OC symptom subscale of the CBCL [109] (as an adult version the OC scale of the YASR [110]), an 8 item screener on OC behaviour, and the SOCS [111], a 7 item screener on presence of OC symptoms, the latter being developed for adolescents between 11 and 18 years. Both screeners have good sensitivity and specificity in general populations of children but specificity is lower in psychiatric populations.

To assess symptoms and severity in clinical samples of children and adults, the Leyton Obsessive Inventory including both adult and children's versions are in use (LOI and LOI-CV; 20 and 11 item versions; yes/no answers and 0-3 answers, respectively) [112-114]. The LOI-CV has a self-report and a parent-derived form, the latter being preferable with respect to sensitivity to pick up OC complaints [115]. Disadvantages are that not all OC symptom domains are captured and that the scores predominantly correspond with compulsion severity and not obsession severity. Further, the Children's Obsessive Compulsive Inventory (CHOCI) has been developed [116], based on Maudsley Obsessive Compulsive Inventory [117] and with severity ratings comparable to the YBOCS severity scale [118]. The CHOCI has 14 symptom items and 6 severity items, and is useful as a severity rater but does not encompass the whole range of $\mathrm{OC}$ symptoms.

The most recommendable instruments to use which capture the full range of OC symptoms and assess OC severity in children as well as adults are the Children's Yale-Brown Obsessive-Compulsive Scale; CY-BOCS (in children)/YBOCS (in adults), entailing 58-80 items on symptoms and 10 severity items [118-120]), and the Obsessive-Compulsive Inventory-Child's Version; OCICV [121] and the adult version: OCI-R [122, 123]. The YBOCS symptom checklist + severity scale have interviewer-based as well as self-report based versions that are equally well in terms of sensitivity and specificity [124], and in children parent-derived versions are used. The (C)Y-BOCS extensively rates presence or absence of lifetime OC symptoms in four domains, of obsessions and checking, washing and contamination, symmetry/ordering behaviour and hoarding [125, 126]. Further, a 10 item severity rating is added, measuring obsession and compulsion severity separately with respect to: time consumingness, distress, interference, resistance and amount of control over obsessions and compulsions. As an extension, 
the Dimensional Y-BOCS (DY-BOCS) has been developed, in which symptom severity is measured separately over each symptom domain and avoidance ratings are added [127]. The YBOCS and DYBOCS scales have good psychometric qualities but are very time consuming; (between 1 and $3 \mathrm{~h}$ to assess symptoms). Therefore, as a much shorter alternative, the 18 item Obsessive Compulsive Inventory-revised version (OCI-R) [123] and as a child version, 21 item the OCI-R CV [121] is recommended. The OCI-R/OCI-CV encompass 18-21 items on OC symptoms in six symptom domains including doubting/checking, washing, ordering, hoarding and neutralising, with ratings between 0 and 4. Test-retest reliability, comparability with YBOCS and construct and divergent validity (i.e. higher correlations are found with measures of anxiety than depression) are all well.

\section{Physical examination}

A general physical and a specialised neurological examination is mandatory to ensure correct diagnosis and exclude severe or progressive neurological disorders [128]. The necessity for any further investigation is determined at this early diagnostic stage. In practice, the typical features of TS virtually rule out alternative major diagnoses. Atypical features such as apparent adult onset or severe deterioration or progression in symptoms should always lead to detailed consideration and investigation to include EEG and neuro-imaging.

Neurological examination is performed to distinguish tics from other movement disorders, most importantly myoclonic dystonias, some forms of epilepsia and stereotypies. In practice, myoclonus-brief shock-like movements of 'non-functional' muscle groups which are not suppressible and usually do not have an associated urgeare the most difficult movements to distinguish from tics. With the presence of sustained or dynamic abnormal postures, it is useful to enquire about and examine for signs of dystonia. A good technique to identify kinesogenic involuntary movements is to for instance observe the writing of the patients; an individual with a myclonic dystonia will need to steady the pen-holding hand with the other to avoid shock-like movements affecting the manoeuvre. Also, observation of fine motor tasks such as putting the lid on a pen is useful to exacerbate/test for myoclonus. Whilst 'dystonic tics' are well recognised, focal or generalised dystonias should not be mistaken for a tic disorder.

Additional investigation with the aid of MRI scanning or EEG is rarely indicated except in those cases where the presentation is not typical in terms of either the semiology of the movement disorder or the presence of features suggestive of the differential diagnoses mentioned above.
Indeed, the more common situation is over-investigation, for instance with EEG in cases where a typical tic disorder is mistaken for epilepsy or myoclonus. It is worthwhile seeking expert opinion if doubt exists about the extent of investigation to pursue. Certain neurological conditions can be associated with tic-like movements (Table 4). It is usually straightforward to differentiate these conditions with a thorough history and examination.

The physical examination includes careful examination for dysmorphic features to identify any indication of genetic syndromes. Unusual features may prompt specific genetic testing by consulting a clinical geneticist. Further, in the presence of additional learning difficulties or autism spectrum diagnosis it might be advisable to consult a clinical geneticist as well, as in some cases this high resolution array might reveal a rare genetic aetiology of these heterogeneous disorders.

\section{Neuropsychological profile and assessment}

Recent research has provided new insights into the neuropsychological profile of children with TS, mainly through direct comparisons between patients with comorbid ADHD, or, to a lesser extent, OCD, and patients with 'uncomplicated' TS, which represents a minority of the clinical population of children with TS. Although the majority of studies indicate that only TS patients with comorbid conditions exhibit cognitive dysfunction on standardised tests, the actual impact of having TS upon social and academic achievement, quality of life and the overall disability burden of the different subgroups of TS requires further study. For this reason, the prognostic value, and, as a consequence, clinical usefulness of formal neuropsychological testing in children with TS has not been clearly established to date, and most neuropsychometric tools seem appropriate, at present, only in research settings. However, it is useful to summarise the findings on cognitive performance in different subgroups of children with TS, and to identify tests that hold promise for standardised neuropsychometric assessment. Table 5 provides an overview of the test batteries suggested from published studies and more ecologically applicable screens (Fig. 1)..

Patients with 'uncomplicated' TS show barely any impairment on all the main areas of cognitive functioning [129-132]. It should also be noted that no ecologically valid measure of manual speed or dexterity (e.g. typing) has been evaluated in children with TS that shows practically relevant results. Of note, enhanced cognitive function has been identified on tasks of response inhibition in TS patients, with children with 'uncomplicated' TS showing enhanced cognitive control on an oculomotor switching task [133]. Authors suggest that this heightened ability to 
Table 5 Tic and comorbidity assessment in children and adults

\begin{tabular}{|c|c|c|c|}
\hline Topic & Measurement instrument children & Measurement instrument adults & Time \\
\hline Demographics & $\begin{array}{l}\text { Age, sex, education level child and } \\
\text { parents, work status parents, ethnicity } \\
\text { child and parents (based on country of } \\
\text { origin info), marital status parents }\end{array}$ & $\begin{array}{l}\text { Age, sex, education level, work status, } \\
\text { ethnicity patient and parents (based on } \\
\text { country of origin info), marital status }\end{array}$ & Max 20 \\
\hline Age at onset tics, OCD, ADHD & Age at onset, age at worst ever & Age at onset, age at worst ever & $\operatorname{Max} 10$ \\
\hline Family history tics/OCD/ADHD & $\begin{array}{l}\text { Family tree including disease in family } \\
\text { members }\end{array}$ & $\begin{array}{l}\text { Family tree including disease in family } \\
\text { members }\end{array}$ & $\operatorname{Max} 20$ \\
\hline Tic diagnosis according to DSM & $\begin{array}{l}\text { Interview (derived from DCI or parts of } \\
\text { DISC) }\end{array}$ & Interview (derived from DCI) & $\operatorname{Max} 10$ \\
\hline Other DSM diagnoses & Kiddie-SADS-PL & MINI/SCID & Max 60 \\
\hline Tic symptoms (past/present) & Y-GTSS (36 items) & Y-GTSS (36 items) & $\operatorname{Max} 30$ \\
\hline OCD symptoms (past/present) & CY-BOCS & Y-BOCS/D-YBOCS & $\operatorname{Max} 30$ \\
\hline ADHD & SNAP/CAARS (parent/teacher/selfrating) & SNAP/CAARS & $\operatorname{Max} 20$ \\
\hline Autism symptoms & Social Responsiveness Scale (SRS) & Autism Questionnaire & $\operatorname{Max} 25$ \\
\hline Impulsive behaviour & BIS 11 & BIS 11 & Max 5 \\
\hline Sensory premonitory urges & PUTS (10 items) & PUTS (10 items) & \\
\hline \multicolumn{4}{|l|}{ Course of psychopathology } \\
\hline Severity-tics & $\begin{array}{l}\text { Y-GTSS }(2 \times 10 \text { items; current } \& \text { worst } \\
\text { ever; age at worst ever })\end{array}$ & $\begin{array}{l}\text { Y-GTSS }(2 \times 10 \text { items; current } \& \text { worst } \\
\text { ever; age at worst ever })\end{array}$ & $\operatorname{Max} 15$ \\
\hline Severity OC symptoms & $\begin{array}{l}\text { CY-BOCS severity }(2 \times 10 \text { items; } \\
\text { current } \& \text { worst ever })\end{array}$ & $\begin{array}{l}\text { Y-BOCS severity }(2 \times 10 \text { items; current } \\
\& \text { worst ever })\end{array}$ & $\operatorname{Max} 10$ \\
\hline Severity depression $\&$ anxiety & RCADS (47 items) & BDI/BAI (42 items) & $\operatorname{Max} 20$ \\
\hline \multirow[t]{2}{*}{ Psychosocial functioning } & CGI & CGI & Max 2 \\
\hline & GTS-QOL (28 items) & GTS-QOL (28 items) & $\operatorname{Max} 15$ \\
\hline Life events & Brugha (29 items) & Brugha (29 items) & Max 15 \\
\hline \multirow{2}{*}{$\begin{array}{l}\text { Estimation of patients' time for } \\
\text { the specific baseline measurements }\end{array}$} & Max 130 & & $\operatorname{Max} 125$ \\
\hline & Max 175 & & $\operatorname{Max} 165$ \\
\hline
\end{tabular}

Brugha list of threatening experiences [153]; DCI Diagnostic Confidence Index [98], DISC Diagnostic Interview Schedule for Children [84, 85], Kiddie-SADS-PL Schedule for Affective Disorders and Schizophrenia for School-Age Children (http://www.wpic.pitt.edu/ksads/default.htm) [83, 87], SCID Structured Clinical Interview on DSM-IV axis I disorders [47, 92], MINI Mini International Neuropsychiatric Interview [93], $C Y$ BOCS Children's Yale-Brown Obsessive Compulsive Scale [119], Y-BOCS Yale-Brown Obsessive Compulsive Scale [118, 120], DY-BOCS Dimensional Yale-Brown Obsessive-Compulsive Scale [127]; SNAP-IV = Swanson, Nolan and Pelham questionnaire, 4th edition [105]; CAARS = Children's version of the Connors ADHD Rating Scale [106]; SRS = Social Responsiveness Scale [154]; BIS = Barratt Impulsivity Scale [155]; PUTS = Premonitory Urge Tics Scale [156]; Y-GTSS = Yale Global Tic Severity Scale [69]; RCADS = [157]; BDI = Beck Depression Inventory-II [158]; BAI = Beck Anxiety Inventory [159]; CGI = Clinical Global Impression [71]; GTS-QOL = Gilles de la Tourette Syndrome-Quality of Life Scale [76]

control inhibition may be a result of tic suppression over time. This finding needs confirmation in subsequent studies. In sum, based on current evidence, no specific clinical neuropsychological assessment is advised in children with 'uncomplicated' TS.

A body of evidence suggests that the main comorbid conditions, ADHD and OCD, have a detrimental influence on the cognitive performance of children with TS [134].

Children with TS + ADHD exhibit cognitive dysfunction. The main negative impact on cognitive performance seems determined by ADHD, independent of the coexisting tic disorder [131]. This might explain why comorbid ADHD is the main predictor of poorer psychosocial health $[135,136]$ and the main determinant of the burden of disability [137] in TS patients. However, it is unclear how much of the negative effects of ADHD on disability and social/academic functioning in TS patients is caused by ADHD-related intellectual dysfunction. ADHD comorbidity seems to impact on the general intellectual function of children with TS, as the majority of reports suggest that a lower Full-Scale IQ is accounted for by the presence of the comorbidity [138-140]. Moreover, learning disabilities and other problems concerning academic achievement are estimated to occur in approximately $23 \%$ of children with a diagnosis of TS and appear to be highly influenced by coexisting ADHD [140, 141]. Specifically, numerical skills [140] and written language [134] have been highlighted as prevalent in TS.

The performance on manual dexterity (Purdue Pegboard test) or visual-motor integration (Beery Visual-Motor 
Integration test) tasks does not differ significantly between patients with TS + ADHD and 'uncomplicated' GTS [132, 142, 143]. In line with children with ADHD only, children with TS + ADHD have been demonstrated to show marked impairment on visual attention (e.g. the Trail Making Test [144]) and sustained attention (Continuous Performance Tests; $[132,145])$. Other cognitive domains in which children with TS + ADHD show impairments, compared to patients with 'uncomplicated' TS, are: planning skills [142, 146], response inhibition [131, 147, 148] and cognitive flexibility/set shifting [35, 148, 149]. The meaning of these cognitive impairments to predict outcome in children with TS remains inconclusive. However, the neuropsychological tests described here-above may provide clinically useful additional information on the cognitive profile of children with TS + ADHD.

There is very limited evidence on the neuropsychological profile of children with TS + OCD. It is unclear whether this comorbidity is associated with selective cognitive impairment in children with TS. The cognitive profile of OCD appears to be one of the primary executive dysfunctions, mainly affecting response inhibition and cognitive flexibility [150]. Although memory may be affected as well, these deficits are thought to be secondary to a failure of organisational strategies during encoding [150]. In line with this, patients with TS + OCD demonstrate executive function deficits primarily in response inhibition [151] and set shifting paradigms [152]. As underscored for the other two TS subgroups, information is lacking on the prognostic indicators of this dysfunction on social, academic and psychological wellbeing in children with TS + OCD. For TS + OCD patients, a neuropsychological assessment focused on executive function, primarily response inhibition and cognitive flexibility, may be clinically indicated.

To conclude, in children who are diagnosed with TS in combination with comorbid ADHD or OCD should undergo neuropsychological evaluation encompassing intellectual function, academic attainments, motor skills, attention, executive function and memory. Neuropsychological tests of certain test-batteries with good psychometric properties for the country in question are suggested from published studies and more ecologically applicable screens.

\section{Conclusion}

Tic disorders represent a wide range of tics and co-existing symptoms with a varied and heterogeneous presentation. In this guideline, we have recommended a broad range of assessments and investigations to capture the tic/TS phenotype, taking developmental issues into account. In our opinion, it is highly advisable to choose instruments that cover the whole age range between infancy and adulthood, so that the time course of symptoms across ages and life stages can adequately be captured. In most situations, a standard interview with a few additional questionnaires and rating scales are sufficient to guide diagnosis and treatment. However, psychiatric comorbidity occurs in more than three quarters of cases that are referred for specialised care. Further, in a minority of cases a more extensive neurological and psychiatric screen is necessary to differentiate tics from other hyperkinetic disorders and from psychogenic disorders. Finally, neuropsychological assessment can be useful because of the high concurrence of tics with learning disorders, especially in children who have not yet finished education or professional training.

Conflict of interest Commercial firms and governmental organisations did not play a role in, or fund, the development of these guidelines. Tammy Hedderly, Jeremy S. Stern, Tara Murphy, Andreas Hartmann, Virginie Czernecki declare that they have no conflict of interest. Danielle C. Cath (last three years): Medical Advisory Board of Lundbeck, the Netherlands; Andrea Ludolph (last three years): she has received lecture fees from Janssen Cilag, and research funding from Novartis, she was/is involved in clinical trials with Böhringer Ingelheim, Eli Lilly, Janssen-Cilag; Mary Robertson has recently received a grant from the Tourette's Action-UK (Grant to support Dr AE Cavanna), she has also received honoraria from Janssen-Cilag, Eli Lilly, and has received Royalties for books from Blackwells Science, David Fulton/Granada/Taylor Francis, Oxford University Press and also Jessica Kingsley Publishers, she also sits on the Medical Advisory Board for the Italian Tourette SyndromeAssociation and The Tourette Syndrome Foundation of Canada; Davide Martino: honoraria for symposia from UCB Pharma, Chiesi Pharmaceuticals, Novartis, and Boehringer-Ingelheim.

Open Access This article is distributed under the terms of the Creative Commons Attribution Noncommercial License which permits any noncommercial use, distribution, and reproduction in any medium, provided the original author(s) and source are credited.

\section{Appendix}

Christos Androutsos, Harald Aschauer, Gillian Baird, Netty Bos-Veneman, Ariana Brambilla, Francesco Cardona, Danielle C. Cath, Andrea Cavanna, Virginie Czernecki, Sandra Dehning, Alan Eapter, Luca Farkas, Julia Gadaros, Andreas Hartmann, Elizabeth Hauser, Isabel Heyman, Tammy Hedderly, Pieter J. Hoekstra, Anne Korsgaard, Georgina M. Jackson, Linnea Larsson, Andrea G. Ludolph, Davide Martino, Claudia Menghetti, Nanette Mol Debes, Norbert Muller, Kirsten Muller-Vahl, Alexander Munchau, Tara Murphy, Richard Musil, Peter Nagy, Judith Nurnberger, Ben Oostra, Perry Paschou, Massimo Pasquini, Kirsten J. Plessen, Mauro Porta, Hugh Rickards, Renata Rizzo, Mary M. Robertson, Veit Roessner, Aribert Rothenberger, Domenico Servello, Liselotte Skov, Jeremy 
S. Stern, Gert Strand, Zsannett Tarnok, Cristiano Termine, Jolande Van der Griendt, Cara Verdellen, Veerle VisserVandewalle, Ebba Wannag, Tomas Wolanczyck.

\section{References}

1. American Psychiatric association (1994) Diagnostic and statistical manual of mental disorder, 4th edn. In: Williams JBW, Spitzer RL (eds) Diagnostic and statisitical manual of mental disorders, third revised edition. 3rd rev ed. American Psychiatric Press, Washington, DC

2. Olson S (2004) Neurobiology. Making sense of Tourette's. Science 305:1390-1392

3. Neuner I, Ludolph A (2009) Tics and Tourette's syndrome throughout the life span. Nervenarzt 80:1377-1387

4. DSM-IV task force (1994) Tic disorders. In: Frances A, Pincus HA, First MB (eds) Diagnostic and statistical manual of mental disorders, 4th edn. American Psychiatric Association, Washington, DC, pp 100-105

5. Schlan der M, Schwarz O, Rothenberger A, Roessner V (2011) Tic disorders: administrative prevalence and co-occurrence with attention-deficit/hyperactivity disorder in a German community sample. Eur Psychiatry (in press)

6. van Woerkom TCAM, Cath DC, Coebergh JA (2007) Tics and the Gilles de la Tourette syndrome. In: Wolters E, van Laar T, Berendse H (eds) Parkinsonism and related disorders. VU University Press, Amsterdam, pp 355-379

7. Mol Debes NM, Hjalgrim H, Skov L (2008) Limited knowledge of Tourette Syndromecauses delay in diagnosis. Neuropediatrics 39:101-105

8. Rothenberger A, Banaschewski T, Roessner V (2007) TicStörungen (Tic disorders) In: Deutsche Gesellschaft für Kinderund Jugend Psychiatrie (ed) Leitlinien zur Diagnostik und Therapie von psychischen Störungen im Säuglings-, Kindesund Jugendalter (Guidelines for diagnostics and therapy of psychic disorders in infancy, childhood and adolescence). Deutscher Artzeverlag, Bonn, pp 319-325

9. Müller-Vahl K, Rothenberger A, Roessner V, Poewe W, Vingerhoets F, Münchau A (2008) Leitlinien für Diagnostik und Therapie: Ticstörungen (Guidelines for diagnostics and therapy: tic disorders). In: Diener HC, Putzki N (eds) Leitlinien für Diagnostik und Therapie in der Neurologi (Guidelines for diagnostics and therapy in neurology). Thieme, Stuttgart, pp 125-129

10. Centers for Disease Control and Prevention (2009) Prevalence of diagnosed Tourette Syndromein persons aged 6-17 years in the United States, 2007. MMWR 58:581-585

11. Stern JS, Burza S, Robertson MM (2005) Gilles de la Tourette's syndrome and its impact in the UK. Postgrad Med 81:12-19

12. Robertson MM, Eapen V, Cavanna AE (2009) The international prevalence, epidemiology, and clinical phenomenology of Tourette syndrome: a cross-cultural perspective. J Psychosom Res 67:475-483

13. Apter A, Pauls DL, Bliech A (1993) An epidemiological study of Gilles de la Tourette's syndrome in Israel. Arch Gen Psychiatry 50:734-738

14. Robertson MM (2008) The prevalence and epidemiology of Gilles de la Tourette syndrome. Part 1: the epidemiological and prevalence studies. J Psychosom Res 65:461-472

15. Leckman JF (2003) Phenomenology of tics and natural history of tic disorders. Brain Dev 25(Suppl 1):S24-S28
16. Shapiro AK, Shapiro ES, Young JG, Feinberg TE (1988) Gilles de la Tourette syndrome, 2nd edn. Raven Press, New York

17. Lin H, Yeh CB, Peterson BS et al (2002) Assessment of symptom exacerbations in a longitudinal study of children with Tourette's syndrome or obsessive-compulsive disorder. J Am Acad Child Adolesc Psychiatry 41:1070-1077

18. Leckman JF, Zhang H, Vitale A et al (1998) Course of tic severity in Tourette syndrome: the first two decades. Pediatrics 102:14-19

19. Pappert EJ, Goetz CG, Louis ED, Blasucci L, Leurgans S (2003) Objective assessments of longitudinal outcome in Gilles de la Tourette's syndrome. Neurology 61:936-940

20. de Groot CM, Bornstein RA, Spetie L, Burriss B (1994) The course of tics in Tourette syndrome: a 5-year follow-up study. Ann Clin Psychiatry 6:227-233

21. Coffey BJ, Biederman J, Geller DA et al (2000) Distinguishing illness severity from tic severity in children and adolescents with Tourette's disorder. J Am Acad Child Adolesc Psychiatry 39:556-561

22. Coffey BJ, Biederman J, Geller D et al (2004) Reexamining tic persistence and tic-associated impairment in Tourette's disorder: findings from a naturalistic follow-up study. J Nerv Ment Dis 192:776-780

23. Bloch MH, Peterson BS, Scahill L et al (2006) Adulthood outcome of tic and obsessive-compulsive symptom severity in children with Tourette syndrome. Arch Pediatr Adolesc Med 160:65-69

24. Bloch MH, Leckman JF (2009) Clinical course of Tourette syndrome. J Psychosom Res 67:497-501

25. Spencer T, Biederman J, Faraone SV et al (2001) Impact of tic disorders on ADHD outcome across the life cycle: findings from a large group of adults with and without ADHD. Am J Psychiatry 158:611-617

26. Peterson BS, Pine DS, Cohen P, Brook JS (2001) Prospective, longitudinal study of tic, obsessive-compulsive, and attentiondeficit/hyperactivity disorders in an epidemiological sample. J Am Acad Child Adolesc Psychiatry 40:685-695

27. Storch EA, Merlo LJ, Lack C et al (2007) Quality of life in youth with Tourette's syndrome and chronic tic disorder. J Clin Child Adolesc Psycho 36:217-227

28. Conelea CA, Woods DW, Zinner SH et al (2011) Exploring the impact of chronic tic disorders on youth: results from the Tourette Syndromeimpact survey. Child Psychiatry Hum Dev (in press)

29. Palermo SD, Bloch MH, Craiglow B et al (2011) Predictors of early adulthood quality of life in children with obsessivecompulsive disorder. Soc Psychiatry Psychiatr Epidemiol (in press)

30. Bloch MH, Leckman JF, Zhu H, Peterson BS (2005) Caudate volumes in childhood predict symptom severity in adults with Tourette syndrome. Neurology 65:1253-1258

31. Stewart SE, Illmann C, Geller DA, Leckman JF, King R, Pauls DL (2006) A controlled family study of attention-deficit/ hyperactivity disorder and Tourette's disorder. J Am Acad Child Adolesc Psychiatry 45:1354-1362

32. Pauls DL, Raymond CL, Stevenson JM, Leckman JF (1991) A family study of Gilles de la Tourette syndrome. Am J Hum Genetics 48:154-163

33. Hebebrand J, Klug B, Fimmers R et al (1997) Rates for tic disorders and obsessive-compulsive symptomatology in families of children and adolescents with Gilles de la Tourette's syndrome. J Psychiatric Res 31:519-530

34. McMahon WM, Van De Wetering BJ, Filloux F, Betit K, Coon H, Leppert M (1996) Bilineal transmission and phenotypic variation of Tourette's disorder in a large pedigree. J Am Acad Child Adolesc Psychiatry 35:672-680 
35. Rothenberger A, Roessner V, Banaschewski T, Leckman JF (2007) Co-existence of tic disorders and attention-deficit/ hyperactivity disorder-recent advances in understanding and treatment. Eur Child Adolesc Psychiatry16 (Suppl 1):1-4

36. Pauls DL (2006) A genome-wide scan and fine mapping in Tourette Syndrome families. Adv Neurol 99:130-135

37. O'Rourke JA, Scharf JM, Yu D, Pauls DL (2009) The genetics of Tourette syndrome: a review. J Psychosom Res 67:533-545

38. Ludolph AG, Juengling FD, Libal G, Ludolph AC, Fegert JM, Kassubek J (2006) Grey-matter abnormalities in boys with Tourette syndrome: magnetic resonance imaging study using optimised voxel-based morphometry. Br J Psychiatry 188:484-485

39. Peterson BS, Staib L, Scahill LD et al (2001) Regional brain and ventricular volumes in Tourette syndrome. Arch Gen Psychiatry 58:427-440

40. Peterson BS, Thomas P, Kane MJ et al (2003) Basal Ganglia volumes in patients with Gilles de la Tourette syndrome. Arch Gen Psychiatry 60:415-424

41. Ludolph AG, Pinkhardt EH, Tebartz van EL et al (2008) Are amygdalar volume alterations in children with Tourette Syndromedue to ADHD comorbidity? Dev Med Child Neurol 50:524-529

42. Plessen KJ, Gruner R, Lundervold A et al (2006) Reduced white matter connectivity in the corpus callosum of children with Tourette syndrome. J Child Psychol Psychiatry 47:1013-1022

43. Moll GH, Heinrich H, Trott GE, Wirth S, Bock N, Rothenberger A (2001) Children with comorbid attention-deficit-hyperactivity disorder and tic disorder: evidence for additive inhibitory deficits within the motor system. Ann Neurol 49:393-396

44. Bohlhalter S, Goldfine A, Matteson S et al (2006) Neural correlates of tic generation in Tourette syndrome: an event-related functional MRI study. Brain 129(Pt 8):2029-2037

45. Wong DF, Brasic JR, Singer HS et al (2008) Mechanisms of dopaminergic and serotonergic neurotransmission in Tourette syndrome: clues from an in vivo neurochemistry study with PET. Neuropsychopharmacology 33:1239-1251

46. Singer HS, Szymanski S, Giuliano J et al (2002) Elevated intrasynaptic dopamine release in Tourette's syndrome measured by PET. Am J Psychiatry 159:1329-1336

47. First MB, Pincus HA (2002) The DSM-IV text revision: rationale and potential impact on clinical practice. Psychiatr Serv 53:288-292

48. Roessner V, Hoekstra PJ, Rothenberger A (2011) Tourette's disorder and other tic disorders in DSM-5: a comment. Eur Child Adolesc Psychiatry 20(2):71-74

49. Walkup JT, Ferrao Y, Leckman JF, Stein DJ, Singer H (2010) Tic disorders: some key issues for DSM-V. Depress Anxiety 27:600-610

50. Gilles de la Tourette GAEB (1885) Etude sur une affection nerveuse caracterisee par la incoordination motrice accompagnee d'echolalie et de coprolalie. Archives Neurologiques 9:19-42; 158-200

51. Freeman RD, Zinner SH, Muller-Vahl KR et al (2009) Coprophenomena in Tourette syndrome. Dev Med Child Neurol $51: 218-227$

52. Lang A (1991) Patient perceptions of tics and other movement disorders. Neurology 41:223-228

53. Cohrs S, Rasch T, Altmeyer S et al (2001) Decreased sleep quality and increased sleep related movements in patients with Tourette's syndrome. J Neurol Neurosurg Psychiatry 70:192-197

54. Mlodzikowska-Albrecht J, Zarowski M, Steinborn B (2007) The symptomatology of tic disorders and concomitant sleep habits in children. Adv Med Sci 52(Suppl 1):212-214

55. Kirov R, Banaschewski T, Uebel H, Kinkelbur J, Rothenberger A (2007) REM-sleep alterations in children with co-existence of tic disorders and attention-deficit/hyperactivity disorder: impact of hypermotor symptoms. Eur Child Adolesc Psychiatry 16(Suppl 1):45-50

56. Kirov R, Kinkelbur J, Banaschewski T, Rothenberger A (2007) Sleep patterns in children with attention-deficit/hyperactivity disorder, tic disorder, and comorbidity. J Child Psychol Psychiatry 48:561-570

57. Cortese S, Faraone SV, Konofal E, Lecendreux M (2009) Sleep in children with attention-deficit/hyperactivity disorder: metaanalysis of subjective and objective studies. J Am Acad Child Adolesc Psychiatry 48:894-908

58. Taylor E (2009) Sleep and tics: problems associated with ADHD. J Am Acad Child Adolesc Psychiatry 48:877-878

59. Bloch MH, Leckman JF, Scott S, Stevenson J, Taylor J, Thapar A (2008) Tic disorders. In: Rutter M, Bishop D, Pine DS (eds) Rutter's child and adolescent psychiatry, 5th edn. Blackwell Publisher Limited, Massachusetts, pp 719-736

60. The Tourette SyndromeClassification Study Group (1993) Definitions and classification of tic Disorders. Arch Neurol 50:1013-1016

61. Leckman JF, Yeh CB, Cohen DJ (2001) Tic disorders: when habit forming neural systems form habits of their own? Zhonghua Yi Xue Za Zhi (Taipei) 64:669-692

62. Leckman JF, King RA, Cohen DJ (1999) Tics and tic disorders. In: Leckman JF, Cohen DJ (eds) Tourette's syndrome: tics, obsessions, compulsions, 1st edn. Wiley, New York, pp 23-42

63. Bliss J (1980) Sensory experiences of Gilles de la Tourette syndrome. Arch Gen Psychiatry 37:1343-1347

64. Banaschewski T, Woerner W, Rothenberger A (2003) Premonitory sensory phenomena and suppressibility of tics in Tourette syndrome: developmental aspects in children and adolescents. Dev Med Child Neurol 45:700-703

65. Cath DC, Spinhoven P, van Woerkom TCAM et al (2001) Gilles de la Tourette's syndrome with and without OCD in comparison to OCD without tics: which symptoms discriminate? J Nerv Ment Dis 189:219-228

66. Miguel EC, Baer L, Coffey BJ et al (1997) Phenomenological differences appearing with repetitive behaviors in obsessivecompulsive disorder and Gilles de la Tourette's syndrome. Br J Psychiatry 170:140-145

67. Cath DC, Hoogduin CAL, van de Wetering BJM, van Woerkom TCAM, Roos RAC, Rooymans HGM (1992) Tourette Syndromeand obsessive-compulsive disorder: An analysis of associated phenomena. In: Chase TN, Friedhoff AJ, Cohen DJ (eds) Advances in neurology series, 58th edn. Raven Press, New York, pp 33-41

68. Cath DC, van de Wetering BJM, van Woerkom TCAM, Hoogduin CAL, Roos RAC, Rooymans HGM (1992) Mental play in Gilles de la Tourette's Syndrome and obsessive-compulsive disorder. Br J Psychiatry 542-545

69. Leckman JF, Riddle MA, Hardin MT et al (1989) The Yale Global tic severity scale: initial testing of a clinician-rated scale of tic severity. J Am Acad Child Adolesc Psychiatry 28:566-573

70. Schaffer D, Gould MS, Brasic J (1983) A children's global assessment scale (CGAS). Arch Gen Psychiatry 40:1228-1231

71. Guy W (1976) Clinical global impression scale ECDEUAssessment manual for psychopharmacology. Publication, Washington DC, USA, pp 76-338

72. Bourredjem A, Pelissolo A, Rotge JY et al (2011) A video clinical global impression scale (CGI) in obsessive compulsive disorder. Psychiatry Res 186(1):117-122

73. Eddy CM, Rizzo R, Gulisano M et al (2011) Quality of life in young people with Tourette syndrome: a controlled study. J Neurol 258(2):291-301

74. Cavanna AE, Schrag A, Morley D et al (2008) The Gilles de la Tourette syndrome-quality of life scale (GTS-QOL): development and validation. Neurology 71:1410-1416 
75. Devinsky O (1995) Outcome research in neurology: incorporating health-related quality of life. Ann Neurology 57:141-142

76. Robertson MM (2000) Tourette syndrome, associated conditions and the complexities of treatment. Brain 123:425-462

77. Kompoliti K, Goetz CG (1998) Hyperkinetic movement disorders misdiagnosed as tics in Gilles de la Tourette syndrome. Mov Disord 13:477-480

78. Leckman JF, Peterson BS, Pauls DL, Cohen DJ (1997) Tic disorders. Psychiatr Clin North Am 20:839-861

79. Achenbach TM, Ruffle TM (2000) The child behavior checklist and related forms for assessing behavioral/emotional problems and competencies. Pediatr Rev 21:265-271

80. Achenbach TM (2000) The young adult self report. Department of Psychiatry, University of Vermont, Burlington, VT

81. Achenbach TM (1991) Manual for the child behavior checklist/ 4-18 and 1991 profile. Department of Psychiatry, University of Vermont, Burlington

82. Rothenberger A, Woerner W (2004) Strengths and difficulties questionnaire (SDQ) - evaluations and applications. Eur Child Adolesc Psychiatry 13(Suppl 2):II1-II2

83. Renou S, Hergueta T, Flament M, Mouren-Simeoni MC, Lecrubier Y (2004) Diagnostic structured interviews in child and adolescent's psychiatry. Encephale 30:122-134

84. Schwab-Stone M, Fisher P, Piacentini J, Shaffer D, Davies M, Briggs M (1993) The Diagnostic Interview Schedule for Children-Revised Version (DISC-R): II. Test-retest reliability. J Am Acad Child Adolesc Psychiatry 32:651-657

85. Shaffer D, Schwab-Stone M, Fisher P et al (1993) The Diagnostic Interview Schedule for Children-Revised Version (DISCR): I. Preparation, field testing, interrater reliability, and acceptability. J Am Acad Child Adolesc Psychiatry 32:643-650

86. Weller EB, Weller RA, Fristad MA, Rooney MT, Schecter J (2000) Children's Interview for Psychiatric Syndromes (ChIPS). J Am Acad Child Adolesc Psychiatry 39:76-84

87. Chambers WJ, Puig-Antich J, Hirsch M et al (1985) The assessment of affective disorders in children and adolescents by semistructured interview. Test-retest reliability of the schedule for affective disorders and schizophrenia for school-age children, present episode version. Arch Gen Psychiatry 42:696-702

88. Malone R, Behar D, Vitiello B, Delaney MA (1986) Reliability and validity of the DICA. J Am Acad Child Adolesc Psychiatry 27:261-262

89. Angold A, Costello EJ (2000) The Child and Adolescent Psychiatric Assessment (CAPA). J Am Acad Child Adolesc Psychiatry 39:39-48

90. Sherrill JT, Kovacs M (2000) Interview schedule for children and adolescents (ISCA). J Am Acad Child Adolesc Psychiatry 39:67-75

91. Cohen P, O'Connor P, Lewis S, Velez CN, Malachowski B (1987) Comparison of DISC and K-SADS-P interviews of an epidemiological sample of children. J Am Acad Child Adolesc Psychiatry 26:662-667

92. First MB (1996) Structured clinical interview for DSM-IV Axis I Disorders. Biometrics Research, New York

93. Sheehan DV, Lecrubier Y, Sheehan KH et al (1998) The MiniInternational Neuropsychiatric Interview (MINI): the development and validation of a structured diagnostic psychiatric interview for DSM-IV and ICD-10. J Clin Psychiatry 59(Suppl 20):22-33

94. Swedo SE, Leonard HL, Garvey M et al (1998) Pediatric autoimmune neuropsychiatric disorders associated with streptococcal infections: clinical description of the first 50 cases. Am J Psychiatr 155:264-271

95. Goetz CG, Leurgans S, Chmura TA (2001) Home alone: methods to maximize tic expression for objective videotape assessments in Gilles de la Tourette syndrome. Mov Disord 16:693-697
96. Chappell PB, McSwiggan Hardin MT, Scahill L et al (1994) Videotape tic counts in the assessment of Tourette's syndrome: stability, reliability, and validity. J Am Acad Child Adolesc Psychiatry 33:386-393

97. Goetz CG, Kampoliti K (2001) Rating scales and quantitative assessment of tics, 85th edn. Lippincott Williams \& Wilkins, New York, pp 31-42

98. Robertson MM, Banerjee S, Kurlan R et al (1999) The Tourette Syndromediagnostic confidence index: development and clinical associations. Neurology 53:2108-2112

99. Walkup JT, Rosenberg LA, Brown J, Singer HS (1992) The validity of instruments measuring tic severity in Tourette's syndrome. J Am Acad Child Adolesc Psychiatry 31:472-477

100. Kompoliti K, Goetz CG (1997) Tourette syndrome. Clinical rating and quantitative assessment of tics. Neurol Clin 15:239-254

101. Storch EA, Murphy TK, Geffken GR et al (2005) Reliability and validity of the Yale Global Tic severity scale. Psychol Assess 17:486-491

102. Shapiro E, Shapiro AK, Fulop G et al (1989) Controlled study of haloperiodol, pimozide, and placebo for the treatment of Gilles de la Tourette's syndrome. Arch Gen Psychiatry 46:722-730

103. Murphy FR, Adler LA (2004) Assessing attention-deficit/ hyperactivity disorder in adults: focus on rating scales. J Clin Psychiatry 65(Suppl 3):12-17

104. Kooij SJ, Bejerot S, Blackwell A et al (2010) European consensus statement on diagnosis and treatment of adult ADHD: the European Network Adult ADHD. BMC Psychiatry 67

105. Harlan E, Clark LA (1999) Short forms of the Schedule for Nonadaptive and Adaptive Personality (SNAP) for self- and collateral ratings: development, reliability, and validity. Assessment 6:131-145

106. Conners CK, Erhardt D, Sparrow E (1999) CAARS adult ADHD rating scales: a technical manual. Multi Health Systems Inc, North Tonawanda, NY

107. Durell T, Adler L, Wilens T, Paczkowski M, Schuh K (2010) Atomoxetine treatment for ADHD: younger adults compared with older adults. J Atten Disord 13:401-406

108. Ward MF, Wender PH, Reimherr FW (1993) The Wender Utah rating scale: an aid in the retrospective diagnosis of childhood attention deficit hyperactivity disorder. Am J Psychiatry 150:885-890

109. Geller D, Doyle R, Shaw D et al (2006) A quick and reliable screening measure for OCD in youth: reliability and validity of the obsessive compulsive scale of the child behavior checklist. Compr Psychiatry 47:234-240

110. Cath DC, van Grootheest DS, Willemsen G, van Oppen P, Boomsma DI et al (2008) Environmental factors in obsessivecompulsive behavior: evidence from discordant and concordant monozygotic twins. Behav Genet 38:108-120

111. Uher R, Heyman I, Mortimore C, Frampton I, Goodman R (2007) Screening young people for obsessive compulsive disorder. Br J Psychiatry 191:353-354

112. Berg CJ, Rapoport JL, Flament M (1986) The Leyton obsessional inventory-child version. J Am Acad Child Psychiatry 25:84-91

113. Bamber D, Tamplin A, Park RJ, Kyte ZA, Goodyer IM (2002) Development of a short Leyton obsessional inventory for children and adolescents. J Am Acad Child Adolesc Psychiatry 41:1246-1252

114. Cooper J (1970) The Leyton obsessional inventory. Psych Med 48-64

115. Stewart SE, Ceranoglu TA, O'Hanley T, Geller DA (2005) Performance of clinician versus self-report measures to identify obsessive-compulsive disorder in children and adolescents. J Child Adolesc Psychopharmacol 15:956-963 
116. Shafran R, Frampton I, Heyman I, Reynolds M, Teachman B, Rachman S (2003) The preliminary development of a new selfreport measure for OCD in young people. J Adolesc 26:137-142

117. Sternberger LG, Burns GL (1990) Maudsley obsessional-compulsive inventory: obsessions and compulsions in a nonclinical sample. Behav Res Ther 28:337-340

118. Goodman WK, Price LH, Rasmussen SA et al (1989) The YaleBrown obsessive-compulsive scale. I. Development, use and reliability. Arch Gen Psychiatry 1006-1011

119. Scahill L, Riddle MA, Swiggin-Hardin M et al (1997) Children's Yale-Brown obsessive compulsive scale: reliability and validity. J Am Acad Child Adolesc Psychiatry 36:844-852

120. Goodman WK, Price LH, Rasmussen SA et al (1989) The YaleBrown obsessive-compulsive scale II validity. Arch Gen Psychiatry 46:1012-1016

121. Foa EB, Coles M, Huppert JD, Pasupuleti RV, Franklin ME, March J (2010) Development and validation of a child version of the obsessive compulsive inventory. Behav Ther 41:121-132

122. Hajcak G, Huppert JD, Simons RF, Foa EB (2004) Psychometric properties of the OCI-R in a college sample. Behav Res Ther $42: 115-123$

123. Huppert JD, Walther MR, Hajcak G et al (2007) The OCI-R: validation of the subscales in a clinical sample. J Anxiety Disord 21:394-406

124. Steketee G, Frost RO, Bogart K (1996) The Yale-Brown obsessive-compulsive scale: interview versus self-report. Behav Res Ther 34:675-684

125. Leckman JF, Grice DE, Boardman J et al (1997) Symptoms of obsessive-compulsive disorder. Am J Psychiatry 154:911-917

126. Katerberg H, Delucchi KL, Stewart SE et al (2010) Symptom dimensions in OCD: item-level factor analysis and heritability estimates. Behav Genet 40:505-517

127. Rosario-Campos MC, Miguel EC, Quatrano S et al (2006) The Dimensional Yale-Brown Obsessive-Compulsive Scale (DYBOCS): an instrument for assessing obsessive-compulsive symptom dimensions. Mol Psychiatry 11:495-504

128. Baird G, Gringras P (2008) Physical examination and medical examination. In: Rutter M, Bishop D, Pine D et al (eds) Rutter's child and adolescent psychiatry, 5th edn. Blackwell Publishing, London, pp 317-335

129. Harris EL, Shuerholz EL, Singer HS et al (1995) Executive function in children with Tourette Syndromeand/or comorbid attention-deficit hyperactivity disorder. J Int Neuropsychol Soc $1: 511-516$

130. Eddy CM, Rizzo R, Cavanna AE (2009) Neuropsychological aspects of Tourette syndrome: a review. J Psychosom Res 67:503-513

131. Roessner V, Becker A, Banaschewski T, Rothenberger A (2007) Executive functions in children with chronic tic disorders with/ without ADHD: new insights. Eur Child Adolesc Psychiatry 16(Suppl 1):36-44

132. Sukhodolsky DG, Landeros-Weisenberger A, Scahill L, Leckman JF, Schultz RT (2010) Neuropsychological functioning in children with Tourette Syndromewith and without attentiondeficit/hyperactivity disorder. J Am Acad Child Adolesc Psychiatry 49:1155-1164

133. Mueller SC, Jackson GM, Dhalla R, Datsopoulos S, Hollis CP (2006) Enhanced cognitive control in young people with Tourette's syndrome. Curr Biol 16:570-573

134. Como PG (2001) Neuropsychological function in Tourette syndrome. Adv Neurol 85:103-111

135. Pringsheim T, Lang AE, Kurlan R, Pearce M, Sandor P (2009) Understanding disability in Tourette syndrome. Dev Med Child Neurol 51:468-472
136. Gorman DA, Thomson T, Plessen KJ, Robertson MM, Leckman JF, Peterson BS (2010) Psychosocial outcome and psychiatric comorbidity in older adolescents with Tourette syndrome: controlled study. Br J Psychiatry 197:36-44

137. Denckla MB (2006) Attention deficit hyperactivity disorder: the childhood comorbidity that most influences the disability burden in Tourette syndrome. Advances in Neurology. Raven Press, New York, pp 17-21

138. Bornstein RA (1990) Neuropsychological performance in children with Tourette's syndrome. Psychiatry Res 33:73-81

139. Schuerholz LJ, Baumgardner TL, Singer HS, Reiss AL, Denckla MB (1996) Neuropsychological status of children with Tourette's syndrome with and without attention deficit hyperactivity disorder. Neurology 46:958-965

140. Huckeba W, Chapieski L, Hiscock M, Glaze D (2008) Arithmetic performance in children with Tourette syndrome: relative contribution of cognitive and attentional factors. J Clin Exp Neuropsychol 30:410-420

141. Burd L, Freeman RD, Klug MG, Kerbeshian J (2005) Tourette Syndromeand learning disabilities. BMC Pediatr 5:34

142. Verte S, Geurts HM, Roeyers H, Oosterlaan J, Sergeant JA (2005) Executive functioning in children with autism and Tourette syndrome. Dev Psychopathol 17:415-445

143. Chang SW, Mc Cracken JT, Piacentini JC (2006) Neurocognitive correlates of child obsessive compulsive disorder and Tourette syndrome. J Clin Exp Neuropsychol 29:724-733

144. Silverstein SM, Como P, Palumbo D, West LL, Osborn LM (1995) Multiple sources of attentional dysfunction in adults with Tourette's syndrome: comparison with attention deficit-hyperactivity disorder. Neuropsychobiology 9:157-164

145. Sherman EM, Shepard L, Joschko M, Freeman RD (1998) Sustained attention and impulsivity in children with Tourette syndrome: comorbidity and confounds. J Clin Exp Neuropsychol 20:644-657

146. Channon S, Gunning A, Frankl J, Robertson MM (2006) Tourette's syndrome (TS): cognitive performance in adults with uncomplicated TS. Neuropsychology 20:58-65

147. Crawford SG, Wilson BN, Dewey D (2001) Identifying developmental coordination disorder: consistency between tests. Phys Occup Ther Pediatr 20(2-3):29-50

148. Crawford S, Channon S, Robertson MM (2006) Tourette's syndrome: performance on tests of behavioural inhibition, working memory and gambling. J Child Psychol Psychiatry 46:1327-1336

149. Watkins LH, Sahakian BJ, Robertson MM et al (2005) Executive function in Tourette's syndrome and obsessive-compulsive disorder. Psych Med 35:571-582

150. Olley A, Malhi G, Sachdev P (2007) Memory and executive functioning in obsessive-compulsive disorder: a selective review. J Affect Disord 104:15-23

151. Yuen T, Bradshaw J, Sheppard D, Lee P, Georgiou-Karistinis N (2005) Inhibition of return in children with Tourette's syndrome and comorbid forms: a preliminary study. Child Neuropsychol 11:393-411

152. Shin MS, Choi H, Kim H, Hwang JW, Kim BN, Cho SC (2008) A study of neuropsychological deficit in children with obsessive-compulsive disorder. Eur Psychiatr 23:512520

153. Brugha TS, Cragg D (1990) The list of threatening experiences: the reliability and validity of a brief life events questionnaire. Acta Psychiatr Scand 82:77-81

154. Constantino JN, Davis SA, Todd RD et al (2003) Validation of a brief quantitative measure of autistic traits: comparison of the social responsiveness scale with the autism diagnostic interviewrevised. J Autism Dev Disord 33:427-433 
155. Barratt ES (1993) Impulsivity: integrating cognitive, behavioral, biological and environmental data. In: Mc Cown WG, Johnson JL, Shure MB (eds) The impulsive client: theory, research and treatment. American Psychological Association, Washington, DC

156. Woods DW, Piacentini J, Himle MB, Chang S (2005) Premonitory Urge for Tics Scale (PUTS): initial psychometric results and examination of the premonitory urge phenomenon in youths with tic disorders. J Dev Behav Pediatr 26:397-403

157. Chorpita BF, Moffitt CE, Gray J (2005) Psychometric properties of the revised child anxiety and depression scale in a clinical sample. Behav Res Ther 43:309-322
158. Joe S, Woolley ME, Brown GK, Ghahramanlou-Holloway M, Beck AT (2008) Psychometric properties of the Beck Depression Inventory-II in low-income, African American suicide attempters. J Pers Assess 90:521-523

159. Steer RA, McElroy MG, Beck AT (1983) Correlates of selfreported and clinically assessed depression in outpatient alcoholics. J Clin Psychol 39:144-149 